\title{
Determining Pull-Out Deformations by Means of an Online Photogrammetry Monitoring System
}

\author{
Emin Özgür Avşar ${ }^{1, *}$, Mehmet Orhan Altan ${ }^{1}$, Ünal Anıl Doğan², Devrim Akça ${ }^{3}$ \\ 1 İTÜ, Civil Engineering Faculty, Department of Geomatic Engineering 34469, MASLAK, ISTANBUL-TR \\ 2 İTÜ, Civil Engineering Faculty, Department of Civil Engineering 34469, MASLAK, ISTANBUL-TR \\ ${ }^{3}$ Işı1k University, Faculty of Engineering, Department of Civil Engineering, 34980, ȘILE, ISTANBUL-TR \\ * Corresponding author \\ Received 22 May 2014 \\ E-mail: avsarem@itu.edu.tr \\ Accepted 10 Jan 2015
}

\begin{abstract}
Chemical anchorages are applied in many engineering implementations, particularly strengthening of reinforced concrete structures. During strengthening procedure; chemical anchorages should be tested, since they supply to transfer the load between existing construction elements and newly added elements. Therefore; the study of the quality of chemical anchorages is an important issue in construction materials science. In this context; the most important experiment is to determine the pull-out loads of embedded anchorage reinforcement by applying axial loads. In this study; it is aimed to determine the displacements of steel reinforcements, embedded into concrete by using chemical anchorages, while applying axial pulling loads. In order to determine the displacements and load - deformation graphs; starting conditions and every 10 bar pressure applied conditions of the steel reinforcements were captured by the cameras. The obtained images were evaluated by using photogrammetric software. Based on the photogrammetric post-processing results, the load - deformation graphs were plotted and the loads at loss of adhesion were determined
\end{abstract}

Keywords: Acquisition, Monitoring, Engineering, Measurement, Camera, Photogrammetry

\section{Introduction}

In strengthening applications such as, column jacketing, and the addition of new shear walls to the existing system on frame axes by replacing brick walls, anchorages are widely used for connecting these new vertical members to the existing structure in order to transfer the loads to the foundations and, to secure the combined resistance of existing and strengthening members. Chemically bonded anchors, which can be described as a rod attached to a pre-drilled hole with construction chemicals, are frequently used in rehabilitation and strengthening applications due to the ease of their applications procedures (Kaya, 2007).

Chemical anchors are the simplest methods for achieving the adherence between existing and new constructed reinforced concrete members. However, strength of these anchors can show great differences with respect to the type of chemical, cleanliness of anchor hole and compressive strength of concrete (Y1lmaz et al., 2010).

Deformation measurement during laboratory testing on construction materials aims at determining the intrinsic characteristics of the considered object. The examination of the deformation and the knowledge of the applied load (e.g., a mechanical or thermal load) allow the analysis of the mathematical model that describes the behavior of a construction element (Barazzetti and Scaioni, 2010).

According to standard "Products and systems for the protection and repair of concrete"; coded EN 1881, deformations corresponding to the axial tensile loads should be measured. In addition to this; in the standard "Products and systems for the protection and repair of concrete structures, Definitions, requirements, quality control and evaluation of conformity, Anchoring of reinforcing steel bar", coded EN $1504-6,0.6 \mathrm{~mm}$ is given as the maximum value 
of deformation for a steel reinforcements which has $16 \mathrm{~mm}$ diameter, under $75 \mathrm{kN}$ load which is applied during the test method defined in EN 1881. Also; load at loss of adhesion can be calculated from load - deformation graphs according to guideline published by European Technology Assessment Group.

In general this study aimed to propose a photogrammetric monitoring network that includes the steps from acquisition to analysis. For understanding the availability of monitoring displacements of an object, indoor test, which installed in the Construction Materials Laboratory of Istanbul Technical University, implemented pull-out deformations test of bonded metal anchors embedded in concrete. In detail; it is aimed to determine the displacements of steel reinforcements, embedded into concrete by using chemical anchorages, while applying axial pulling loads.

\section{Chemical Anchorages and Deformation Deformation of Anchorages}

Knowledge of structural behaviour of anchorage under the applied axial tension is essential for safe design. In the retrofitting applications; compatibility of the additional elements to the supporting system of the existing structure and providing a safe load transfer depends on the performance of the implemented anchors. Anchorages transfer the tensile loads throughout the cohesive depth of the anchorage. Adherence can be called as the shear stresses that provide bonding between reinforcements and epoxy or concrete and epoxy. Components of adherence in chemical anchorages can be considered as; friction force, chemical bond strength and mechanical gear force occurred as the results of ribs on the anchorage. During the pull-out tests; various failure modes may be observed depending on the concrete class, type of chemical anchorage, geometry of the anchorage, durability and depth of the anchorage (Figure 1).

Behavior of anchors; under the influence of the axial tensile load, can be classified in five categories:

1. Flowing/Rupturing of Anchorage reinforcement: This situation is the preferred one for the designer.

2. Pull out of Anchorage reinforcement: Chemical anchors begin to pull out along the anchoring depth, with the ending of the adhesion strength.

3. Conic Rupturing of the concrete: Provided tensile stress exceeds the tensile strength of concrete; conical failure of the anchored concrete may take place.

4. Simultaneous Pull-out and Conic Rupturing

5. Splitting of the concrete: Where the depth of the base element is shallow or planting the anchorage near the edge may cause splitting of the concrete.
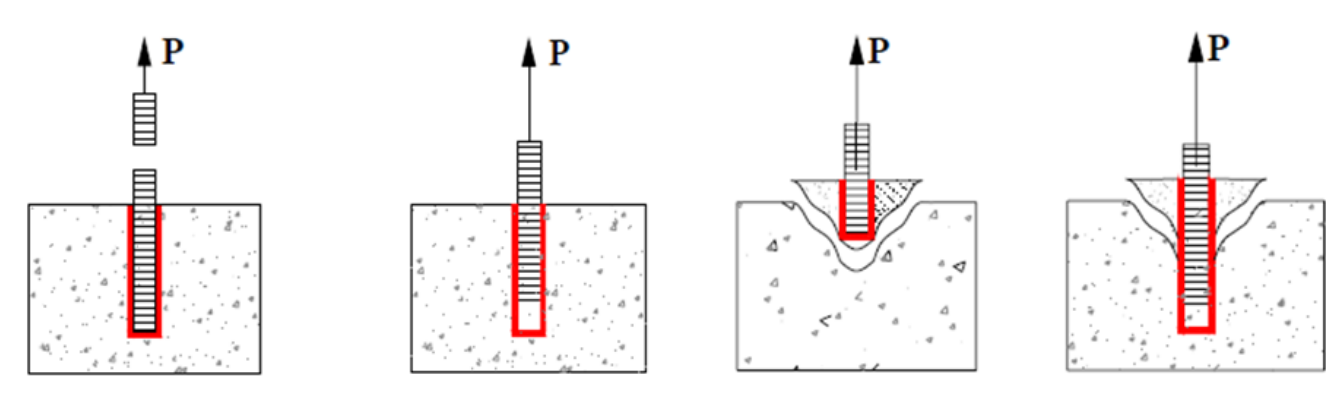

Fig 1. Study Area and Landslides of study area and Devebağırtan Valley 


\section{Deformation Measurement Techniques}

One of the most important objectives of geodetic and photogrammetric measurements is analysing of deformation occurring depending on time, affected factors and strengths on natural and artificial (man-made) objects (Bogatin et al., 2008).

The basic process steps to be followed for monitoring deformations of engineering structures can be expressed as follows:

Determination of the performance
-
Ptate) of the structure,
Positioning accuracy requirement and
selection of the method,
Type and number of measurements
Tools and equipment selection,
Measuring and data collection,
Evaluation of data and analysis,
Determination of the behavior of the
deformations within the time, location
and frequency,
Modelling,
Reporting.

Several instruments can be used to measure the deformations of structural elements during loading tests. However, the most widely adopted tools are linear-variable-differentialtransformers (LVDTs) and strain gauges, which provide the magnitude of the displacement with the investigation of the changes of electrical resistance due to a load. These tools are considered proven techniques, with an accuracy of $\pm 1 \mu \mathrm{m}$ or even less, and they give real-time data. On the other hand, they only provide $1 \mathrm{D}$ measurements limited to the area in which the sensor is fixed. In addition, a connection with a control unit is necessary and after destructive tests these kinds of sensors can be damaged. Thus, LVDTs or strain gauges are not a convenient choice in the case of extensive analysis on the whole body, in which a great number of 3D points with a good spatial distribution must be measured (Barazzetti and Scaioni, 2010).

In these cases, techniques of digital photogrammetry depict a valuable option for the design of powerful and flexible measurement tools. The use of photogrammetry in material testing experiments will generally allow for the simultaneous measurement of deformation or displacements at an almost arbitrary number of locations over the camera's field of view. Data processing can be highly automated and fast, allowing for real-time monitoring at the camera imaging rate (Maas and Niederöst, 1997; Albert et al., 2002; Maas and Hempel, 2006)

\section{System Design}

All engineering projects should begin with the determination of expectations and a design that fulfilling these expectations. A photogrammetric system mainly begins with the determination of the camera-lens set that will provide adequate field of view and standard deviations. In addition to this, camera and target locations should be specified. Generally, this first step called as network design and simulation tests are performed to realize the designed network.

Hence, monitoring systems include image acquisition, target recognition, computation of the object coordinates of the targets and analysis, accordingly. The below diagram summarizes the steps of the followed design in this project.

Image acquisition step was carried out by generating a Matlab code (Figure 3). For this purpose a camera file, also known as a device configuration file was created by using camera configuration toolbox supported by the camera distributor. This camera file introduces the basics of the camera to Matlab such as: Camera name, running mode, maximum resolution, number of bits, maximum frames per seconds and cable connections.

The other required parameters should be determined by the algorithm as; camera port, trigger configuration, trigger repetition, frames per trigger, region of interest position, logging, starting-stop-deleting, number of frames per second will be grabbed. For image synchronization; a "for" loop was created that provides starting image acquisition at the same time for each cameras. In addition; advantage of parallel computing was used by the Matlab pools. Since the data is provided from more than one sensor, there would be time differences between acquisition times. 
Therefore; time component of the data acts an image acquisition. important role and should be recorded with

\section{A. Camera Configuration}
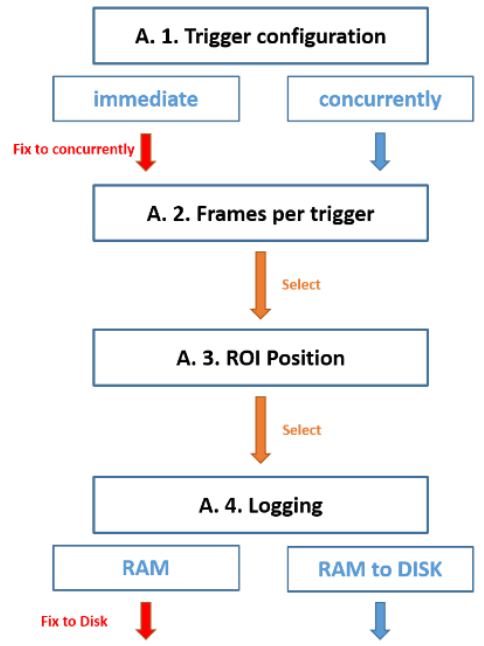

B. Data Acquisition

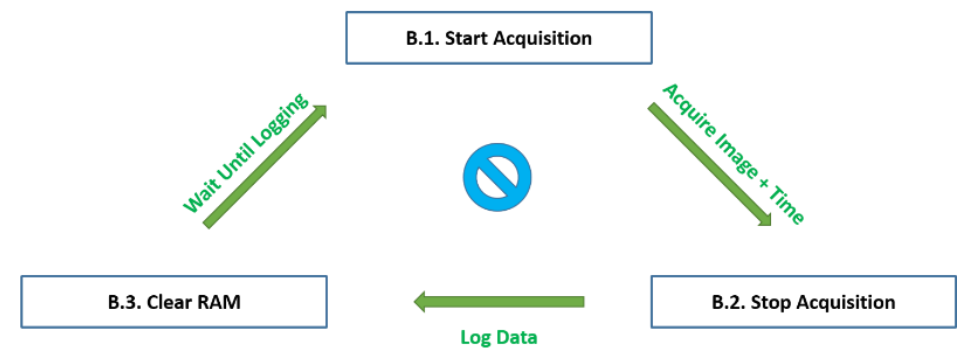

Until decided turn

C. Data Process

C. 1. Synchronized Pairs

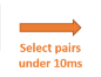

C. 2. Image Segmentation

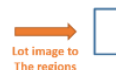

C. 3. Cross Correlation

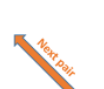

C. 5. Object Coordinates
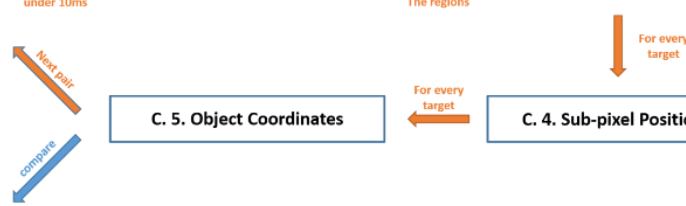

C. 4. Sub-pixel Positioning

C. 6. Spatial Displacement

Fig. 2. Flowchart diagram. 
Furthermore, for calculating the exact coordinates of the target points, the mathematical formulas, based on co-linearity condition of photogrammetry, that describe the relationship between image and object coordinates should be used. Since these formulas are not linear, differential equations should be obtained by linearization. Differential equations can be solved iteratively by calculating the corrections according to least square adjustment. Definite outer orientation parameters and object coordinates of the targets can be calculated by applying the calculated corrections to the previous values. This iterative approach requires preliminary values and these values acquired from field measurements. A Matlab code was written and used for these photogrammetric evaluation steps.

\section{Experiments and Discussion}

The test field was established in the Construction Materials Laboratory of Istanbul Technical University. Two steel reinforcements with $16 \mathrm{~mm}$ diameter and two with $20 \mathrm{~mm}$ diameter were observed during the experiment. All of the reinforcements were all embedded in the concrete with a depth of ten times of their diameters within a C30 grade concrete (Figure 4).

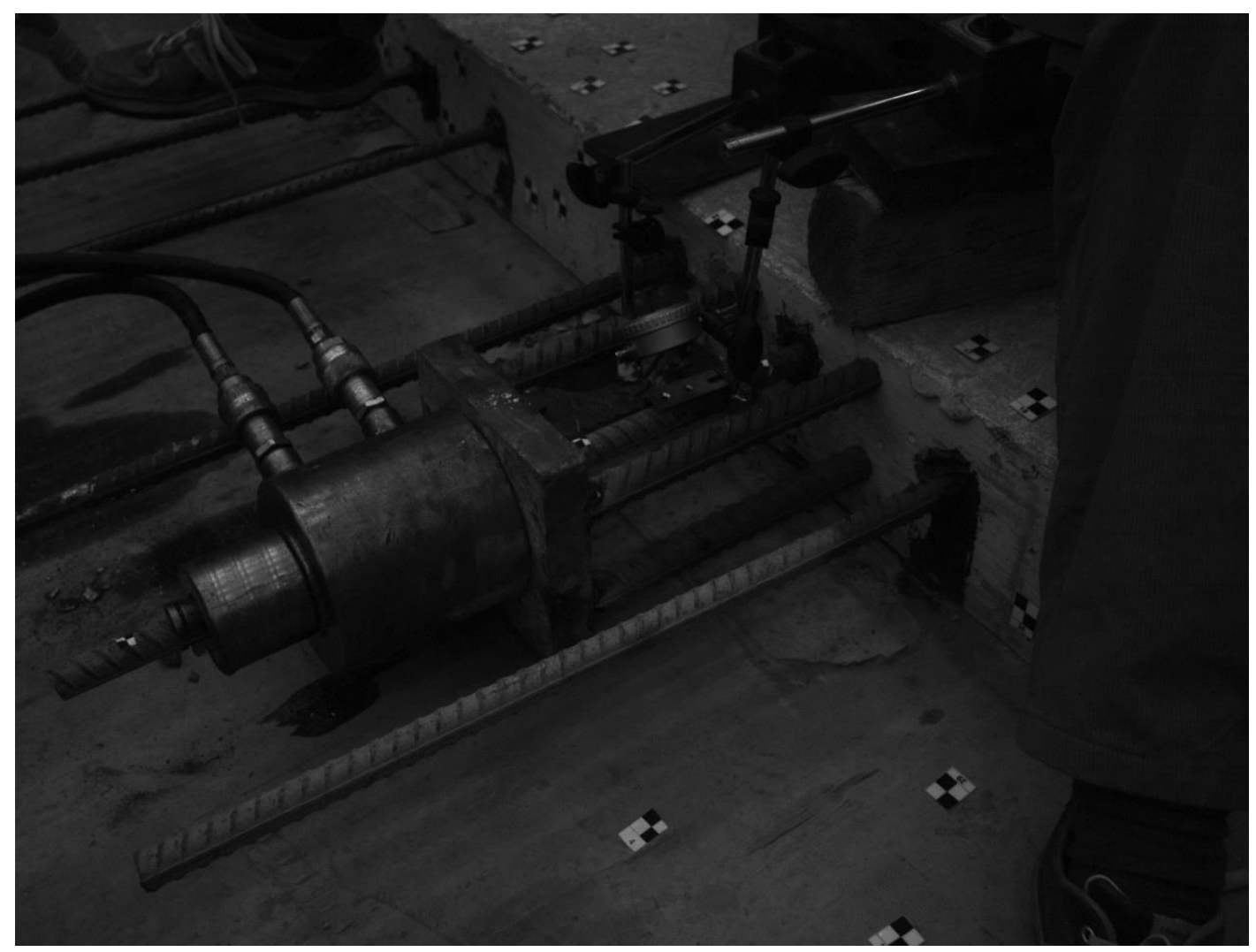

Fig.4. Test field

The monitoring system consists of two Basler A402K Area Scan Cameras, Matrox Intellicam Image Acquisition Software, BAAP and/or Pictran Photogrammetric Software and the operating system is Windows XP. The size of CCD is $16.46 \mathrm{~mm} \times 12.08 \mathrm{~mm}$, the pixel size is $7 \mu \mathrm{m} \times 7 \mu \mathrm{m}$, the resolution is $2352 \times 1726$ pixels, and the optical lens is CARL ZEISS prime lens of $18 \mathrm{~mm}$ (Figure 3). The cameras were calibrated by using the test field in ITU Photogrammetry Laboratory.

The process of measurement can be defined as following: 
1. A few randomly distributed ground controls points were measured with an accurate TPS.

2. 3 artificial points were established on the reinforcement.

3. Images were recorded from camera stations under empty load. The 3D coordinates of targets on the steel reinforcement are computed. The result is defined as the basic stage.

4. Increase the pressure continuously by 10 bars on the steel reinforcements and wait till the deformation is stable.

5. Images were grabbed.

6. Steps 4-5 are repeated until the reinforcements get free of the concrete.

During the experiments, displacements were occurred under 130, 128, 184 and $189 \mathrm{kN}$ loads for reinforcements with 16 and $20 \mathrm{~mm}$ diameter, respectively. Therefore 31 images pairs for the reinforcements $16 \mathrm{~mm}$ diameter and 45 images pairs for the $20 \mathrm{~mm}$ pairs were grabbed.

Post-processing evaluation of image pairs for reinforcements carried-out. The acquired displacements and displacement-load curves are given (Table 1 and 2, Figure 5). Since the coefficient of the pressure-load equation of the hydraulic cylinder is $\mathrm{k}=41.794$, loads were calculated with:

$$
F(k N)=\frac{P(\text { bar }) * k * g}{1000}
$$

Table 1. Observed displacements for the $16 \mathrm{~mm}$ diameter reinforcements.

\begin{tabular}{rrrrrr}
\hline \multicolumn{1}{l}{$\begin{array}{l}\text { Load } \\
(\mathrm{kN})\end{array}$} & \multicolumn{1}{c}{ Disp } & \multicolumn{1}{c}{$(\mathrm{mm})$} & \multicolumn{1}{l}{ Load } & \multicolumn{1}{l}{ Disp } & \multicolumn{1}{c}{$(\mathrm{mm})$} \\
\hline 4.1 & 0.005 & 0.002 & 65.6 & 0.165 & 0.165 \\
8.2 & 0.01 & 0.004 & 69.7 & 0.18 & 0.178 \\
12.3 & 0.014 & 0.006 & 73.8 & 0.195 & 0.19 \\
16.4 & 0.02 & 0.01 & 77.9 & 0.21 & 0.202 \\
20.5 & 0.031 & 0.021 & 82 & 0.23 & 0.215 \\
24.6 & 0.045 & 0.035 & 86.1 & 0.263 & 0.23 \\
28.7 & 0.058 & 0.048 & 90.2 & 0.325 & 0.25 \\
32.8 & 0.07 & 0.06 & 94.3 & 0.554 & 0.277 \\
36.9 & 0.08 & 0.073 & 98.4 & 0.925 & 0.33 \\
41 & 0.09 & 0.085 & 102.5 & 1.356 & 0.988 \\
45.1 & 0.1 & 0.097 & 106.6 & 1.87 & 1.975 \\
49.2 & 0.11 & 0.11 & 110.7 & 2.452 & 2.618 \\
53.3 & 0.119 & 0.125 & 114.8 & 3.095 & 3.295 \\
57.4 & 0.13 & 0.14 & 118.9 & 3.776 & 4.217 \\
61.5 & 0.147 & 0.153 & 123 & 4.505 & 5.34 \\
\hline
\end{tabular}

As given in "Guideline for European Technical Approval of Metal Anchors for Use in Concrete Part Five: Bonded Anchors"; with bonded anchorages uncontrolled slip occurs when the mortar with the embedded part is pulled out of the drilled hole (because then the load displacement behavior depends significantly on irregularities of the drilled hole). The corresponding load when uncontrolled slip starts is called load at loss of adhesion $\mathrm{Nu}$ _adh. 
$\mathrm{Nu}$ _adh shall be evaluated for every test from the measured load displacement curve (EOTA, 2008). By investigating the obtained load displacement graphs of the reinforcements; it was observed that the acquired curves were seen to be similar with the first example given in ETAG Guideline, which means load at loss of adhesion by a significant change of stiffness. Although the reinforcements carries more load until pulling-out; the critical $\mathrm{Nu}$ _adh values and corresponding displacements were calculated and given in the table 3 .

Table 2. Observed displacements for the $20 \mathrm{~mm}$ diameter reinforcements.

\begin{tabular}{|c|c|c|c|c|c|}
\hline $\begin{array}{l}\text { Load } \\
(\mathrm{kN})\end{array}$ & $\begin{array}{l}\text { Disp } \\
20-1\end{array}$ & $\begin{array}{l}(\mathrm{mm}) \\
20-2\end{array}$ & $\begin{array}{l}\text { Load } \\
(\mathrm{kN})\end{array}$ & $\begin{array}{l}\text { Disp } \\
20-1\end{array}$ & $\begin{array}{l}(\mathrm{mm}) \\
20-2\end{array}$ \\
\hline 4.1 & 0.082 & 0.001 & 94.3 & 0.591 & 0.303 \\
\hline 8.2 & 0.145 & 0.005 & 98.4 & 0.630 & 0.320 \\
\hline 12.3 & 0.192 & 0.016 & 102.5 & 0.667 & 0.332 \\
\hline 16.4 & 0.225 & 0.030 & 106.6 & 0.705 & 0.345 \\
\hline 20.5 & 0.241 & 0.040 & 110.7 & 0.746 & 0.368 \\
\hline 24.6 & 0.255 & 0.050 & 114.8 & 0.790 & 0.390 \\
\hline 28.7 & 0.273 & 0.067 & 118.9 & 0.837 & 0.400 \\
\hline 32.8 & 0.290 & 0.085 & 123.0 & 0.890 & 0.410 \\
\hline 36.9 & 0.305 & 0.098 & 127.1 & 0.958 & 0.423 \\
\hline 41.0 & 0.320 & 0.110 & 131.2 & 1.030 & 0.440 \\
\hline 45.1 & 0.338 & 0.122 & 135.3 & 1.090 & 0.464 \\
\hline 49.2 & 0.355 & 0.135 & 139.4 & 1.155 & 0.495 \\
\hline 53.3 & 0.370 & 0.150 & 143.5 & 1.227 & 0.529 \\
\hline 57.4 & 0.385 & 0.165 & 147.6 & 1.340 & 0.590 \\
\hline 61.5 & 0.402 & 0.180 & 151.7 & 1.746 & 1.359 \\
\hline 65.6 & 0.420 & 0.195 & 155.8 & 2.310 & 2.535 \\
\hline 69.7 & 0.440 & 0.210 & 159.9 & 2.763 & 3.389 \\
\hline 73.8 & 0.460 & 0.225 & 164.0 & 3.225 & 4.230 \\
\hline 77.9 & 0.479 & 0.240 & 168.1 & 3.736 & 5.137 \\
\hline 82.0 & 0.500 & 0.255 & 172.2 & 4.280 & 6.060 \\
\hline 86.1 & 0.525 & 0.270 & 176.3 & 4.852 & 6.973 \\
\hline 90.2 & 0.555 & 0.285 & 180.4 & 5.455 & 7.885 \\
\hline
\end{tabular}
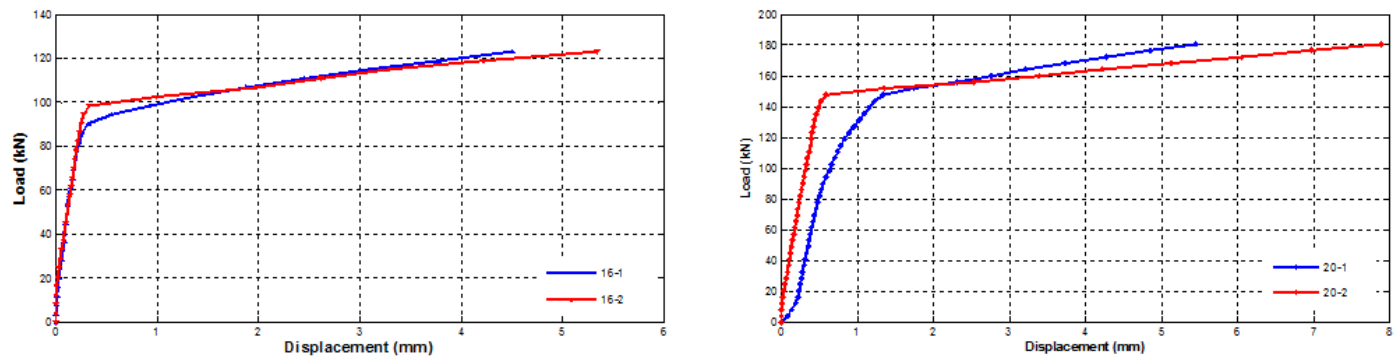

Fig. 5. Displacement-Load Curves. 
Table 3. $\mathrm{N}_{\mathrm{u} \_a d h}$ values and displacements.

\begin{tabular}{rrr}
\hline \hline Reinforcement & \multicolumn{1}{c}{$\begin{array}{c}\mathrm{N}_{\mathrm{u} \_ \text {adh }} \\
(\mathrm{kN})\end{array}$} & $\begin{array}{c}\text { Displacement } \\
(\mathrm{mm})\end{array}$ \\
\hline 16.Oca & 86.96 & 0.273 \\
16.Şub & 95.78 & 0.290 \\
20.Oca & 145.10 & 1.262 \\
20.Oca & 146.9 & 0.573 \\
\hline
\end{tabular}

\section{Conclusion}

This paper proposed a monitoring and photogrammetric evaluation suite, and investigates the monitoring of the load displacement curves of chemically bonded metal anchors installed in concrete by means of photogrammetry. According to the evaluation of the captured photos by using photogrammetric software, typical load displacement curves are obtained. Duplicated curves of each anchor diameter are coherent with each other. Deformations are less than 0.6 $\mathrm{mm}$ at $75 \mathrm{kN}$ axial load, and these results comply with the standard EN 1504-6.

Loads at loss of adhesion increased by increasing diameter, in turn, increasing anchor depth. Besides, it should be noted that, each anchor is pulled out at a load of $20 \%$ more than adhesion loss load.

\section{References}

ACI Committee 355, (1991). State-of-The-ArtReport on Anchorage to Concrete, ACI 355.1R-91, American Concrete Institute, Detroit.

Albert, J., Maas, H.-G., Schade, A., Schwarz, W., (2002). Pilot studies on photogrammetric bridge deformation measurement, Proceedings of the 2nd IAG Commission IV Symposium on Geodesy for Geotechnical and Structural Engineering, 21-24 May, Berlin, Germany.

Barazzetti, L., Scaioni, M., (2010). Development and Implementation of Imagebased Algorithms for Measurement of Deformations in Material Testing, Sensors 2010, 10, 7469-7495; doi: 10.3390/s 100807469 .
European Organisation for Technical Approvals, (2008). ETAG 001, Edition March 2002, Guideline for European Technical Approval Of Metal Anchors For Use In Concrete, Amended November 2006, Second Amendment February 2008, Part Five: Bonded Anchors.

Kaya, Y., (2007). Pull-out behaviour of partially bonded anchors to be used in retrofitting existing structures under anchorage interface conditions, $\mathrm{MsC}$ Thesis, ITU Institute for Science and Technology, 2007, Istanbul, Turkey.

Maas, H.-G., (2006). Photogrammetric Techniques in Civil Engineering Material Testing and Structure Monitoring, Photogrammetric Engineering \& Remote Sensing Vol. 72, No. 1, January 2006, pp. 39-45.

Maas, H.-G., and M. Niederöst, (1997). The accuracy potential of large format still video cameras, Videometrics V (S. El Hakim, editor), SPIE Proceedings Series, Volume 3174.

Yılmaz, S., Caliskan, O., Kaplan, H., Kirac, N., (2010). Factors Affecting the Strength of Chemical Anchors, Journal of Engineering and Architecture Faculty of Eskisehir Osmangazi University, Vol: XXIII, No:1. 